Cuadernos de Filología Clásica. Estudios Latinos

ISSN: 1131-9062

http://dx.doi.org/10.5209/CFCL.60931

\title{
La injusticia social en las fábulas de Fedro: origen y tradición
}

\author{
Antonio Cascón Dorado ${ }^{1}$
}

Recibido: 4 de noviembre de 2017 / Aceptado: 30 de junio de 2018

Resumen. Hace ya tiempo que los estudiosos de la obra de Fedro consideran la defensa de los humildes y el ataque a los poderosos una de las señas de identidad de sus fábulas. Tras recordar los apólogos en los que esa perspectiva social se pone de manifiesto y mostrar la coherencia de su pensamiento, constataremos su originalidad en la tradición fabulística, comparando sus ideas con las que encontramos en Babrio, La Augustana o Aviano. Ese pensamiento tan llamativo y coherente de Fedro no tiene que ver con la crítica contra el poder que aparece en algunas fábulas de la tradición esópica y que suele atribuirse a la influencia cínica. Pensamos que esa forma de pensar tiene su origen, además de en las difíciles circunstancias de su vida, en la influencia de la corriente más progresista del pensamiento estoico, representada por filósofos como Esfero, Antípatro o Blosio. El análisis de algunas de las más relevantes colecciones medievales y modernas hace evidente que sus ideas en este tema no han sido asumidas por los continuadores de su obra.

Palabras clave: Humiles et potentes; tradición fabulística; influjo estoico.

\section{[en] Social injustice in Phaedrus's fables: origin and tradition}

\begin{abstract}
Phaedrus's have long considered the defense of the poor and the attack on the rich and powerful as distinguishing features of his fables. After presenting the texts where this social perspective is expressed and showing the coherence of his way of thinking, I will demonstrate the originality of his ideas within fable tradition, by contrasting them to those we find in Babrius, la Augustana or Avianus. Phaedrus's remarkable and coherent thoughts have nothing to do with the criticism against power that we find in some fables in the Aesopian tradition and which is commonly associated with the influence of the Cynics. My claim is that this way of thinking is influenced, as well as by his difficult life circumstances, by the most progressive strand of stoical thinking, as represented by philosophers such as Espherus, Antipatrus or Blosius. The analysis of some of the most relevant medieval and modern collections of texts clearly shows that Phaedrus's ideas were not taken on by his followers.
\end{abstract}

Key words: Humiles et potentes; fable tradition; stoic influence.

Sumario: Introducción. 1. Humiles et potentes en las fábulas de Fedro. 2. Coherencia de ideas: justicia imposible y desigualdad inevitable. 3. La propuesta de Fedro. 4. El tema en las colecciones fabulísticas antiguas. 5. El origen de las ideas de Fedro. 6. El tema en los fabulistas continuadores de Fedro. 7. Conclusiones. Bibliografía

Cómo citar: Cascón Dorado, A., «La injusticia social en las fábulas de Fedro: origen y tradición», Cuad. Filol. Clás. Estud. Lat. 38.1 (2018), 23-40.

Universidad Autónoma de Madrid

antonio.cascon@uam.es 


\section{Introducción}

Sin duda, la denuncia de la desigualdad social es uno de los aspectos más llamativos de la obra del fabulista latino. La imagen que nos han trasmitido de este poeta algunos manuales de Literatura Latina es la del hombre que defiende a los humildes y muestra su amargura ante una sociedad que no le gusta, particularmente Rostagni $(1964,253)$, que titula así su capítulo dedicado al fabulista: Fedro, poeta degli humili ${ }^{2}$. Así lo reconoce también uno de los mejores estudiosos de sus fábulas, M. Nøjgaard (1967, 172 y 176), quien afirma que es «el único autor de la antigüedad que se proclama proletario» y que «el problema social es lo que proporciona un interés duradero a su obra». También La Penna (1961 y 1974), quien identifica la moral de la fábula con la de las clases humildes, concediendo en este punto un lugar relevante a Fedro. El conflicto entre humiles et potentes adquiere también relevancia destacada en la obra de Luzzatto (1976), y, más recientemente, Renda (2012) considera que el mensaje de Fedro solo puede entenderse desde esa perspectiva social. Pero quizá tenga más importancia que un historiador, no especializado en la obra del fabulista, como Gaudemet $(1967,553)$, señalase al tratar el tema de la esclavitud, el carácter excepcional de la obra de Fedro, considerándola la única fuente válida para conocer la mentalidad de los humildes en la Roma imperial. Si este rasgo de sus fábulas ha sido subrayado es, sin duda, por lo que tiene de excepcional en la literatura romana. Es muy difícil encontrar ideas parecidas en los textos clásicos conservados. Difícil, sobre todo, encontrar alguna otra obra donde se acumulen tan claramente los ataques contra el poderoso y la defensa de los débiles, incluyendo incluso recomendaciones de venganza contra la injusticia. Sin embargo, un reciente trabajo de la profesora Mordeglia (2014), convincente en algunos aspectos, pone en duda la originalidad de nuestro poeta en este punto, considerando que no es particularmente relevante frente a la tradición griega anterior, poniendo en duda que nuestro autor fuese realmente liberto y señalando que en muchos casos la diatriba de Fedro es más moral que sociológica y en último extremo dependiente de principios cínico-estoicos ${ }^{3}$. Este nuevo punto de vista nos impulsa a volver sobre el tema, centrándonos, claro está, en el aspecto donde creemos reside su originalidad: la denuncia de la injusticia social y no tanto la confrontación con el poder establecido, que, a nuestro modo de ver y en contra de lo que puede parecer (Henderson 2001), tiene en su obra una importancia secundaria ${ }^{4}$.

Veamos, en primer lugar, en qué fabulas y de qué modo aborda Fedro el tema.

\section{Humiles et potentes en las fábulas de Fedro.}

En su versión de la conocida fábula del reparto del león (1.5) Fedro identifica al poderoso con el malvado (sic totam praedam sola improbitas abstulit) y desaconseja la

\footnotetext{
La misma imagen proyectan otros manuales de Literatura Latina, como los de Bieler o Büchner.

Esta autora defiende que las alusiones a la esclavitud que aparecen en la obra de Fedro son sobre todo de orden literario. Fedro intentaría presentarse como la réplica romana del esclavo filósofo Esopo.

4 No hay en las fábulas de Fedro una actitud contraria a las instituciones político-sociales. En sus fábulas se critica la injusticia social y se ataca al poderoso, pero se respeta la religión, se defiende la familia, se elogia a políticos como Augusto o Tiberio... Su propuesta no es la anarquía o el rechazo de la vida en sociedad, sino, como vamos a ver, la denuncia de los comportamientos injustos, malvados o equivocados
} 
alianza con él en cualquier situación (nunquam est fidelis cum potente societas) ${ }^{5}$. En 2.6 vuelve a referirse a los poderosos, contra los que nunca se está suficientemente protegido (contra potentes nemo est munitus satis); se trata de la fábula del águila y la corneja, unidas para destruir la resistencia de la tortuga, un ejemplo con el que el fabulista pretende demostrar cómo la alianza del malvado y el poderoso resulta invencible (uis et nequitia quicquid oppugnant ruit). En 1.30, Las ranas que temían los combates de los toros, Fedro intenta demostrar que son los humildes quienes pagan las consecuencias de las disputas que entre sí mantienen los poderosos (Humiles laborant, ubi potentes dissident) ${ }^{6}$. En 1.28, con el ejemplo de la zorra que recupera con su sagacidad las crías que el águila le había arrebatado, el fabulista incita la venganza del humilde contra los que abusan de su situación privilegiada (quamuis sublimes debent humiles metuere,/uindicta docili quia patet sollertiae).

$\mathrm{Si}$ el león representa por antonomasia al poderoso en las fábulas -aunque como hemos visto el rol pueda ser jugado por otros animales: águila, toro, etc.-, la oveja y el cordero constituyen el ejemplo preferido para señalar a la víctima de la injusticia. En 1.5, al hacer relación de los animales que se asocian al león para ir de caza, Fedro singulariza el carácter sufridor de la oveja: uacca et capella et patiens ouis iniuriae. Es la oveja la que sufre particularmente la injusticia, como en 1.17, donde acusada falsamente por un lobo y un perro es obligada a pagar lo que no debía (ouis damnata falso testimonio, quod non debebat soluit). También en 1.1, donde el cordero, que no había cometido ningún delito, no consiguió evitar su injusta muerte (iniusta nece) a manos del lobo; la moraleja del apólogo se dirige contra los que con argumentos falsos dañan a quienes no han hecho ningún mal (qui fictis causis innocentes opprimunt).

Esta perspectiva social se pone de manifiesto también en otros relatos (Stocchi, 2005), como 1.15, en cuyo promitio Fedro incide en la escasa incidencia que tienen en el pobre los cambios de gobierno (in principatu commutando saepius/ nil praeter domini nomen mutant pauperes); la fábula cuenta cómo al asno le importa poco quién sea su dueño, ya que el nuevo le tratará de la misma forma que el anterior: «¿qué me importa a mí a quien sirva mientras siga llevando una sola albarda?»7. El conocido apólogo de la rana que, inflándose para ser como el buey, reventó, adquiere en la moraleja de Fedro (1.24) un marcado matiz social: el pobre nunca podrá igualarse al poderoso (Inops, potentem dum uult imitari, perit) ${ }^{8}$. Tambén en 4.6 , donde se cuenta cómo los generales de los ratones, impedidos por sus aparatosos adornos, no pueden esconderse en su agujero ante el ataque de las comadrejas. El epimitio señala las ventajas de la plebe en los grandes desastres: populum tristis euentum premit, / periclinatur magnitudo principum;/ minuta plebs facili praesidio latet.

A las fábulas comentadas hasta aquí podríamos añadir otros apólogos perdidos de Fedro que nos es posible reconstruir gracias a las paráfrasis medievales derivadas de su obra. Entre las 32 paráfrasis medievales que los especialistas consideran parte de la obra perdida de Fedro hay algunas donde volvemos a encontrar el conflicto entre humiles et potentes tan característico de nuestro autor. La atribución a Fedro de

En esta fábula los aliados del león conforman una especie de jerarquía social: la vaca, la cabra y la oveja. Tal vez en su intento por demostrar la jerarquización de la sociedad Fedro se olvidó de que se trataba de animales herbívoros que no necesitaban la carne de un ciervo.

${ }_{6}$ La moraleja recuerda el famoso verso de Horacio: quidquid delirant reges, plectuntur Achiui. (Epist. 1. 2.14).

Para Fedro y también para Aviano y Rómulo seguimos la traducción de Cascón (2005).

8 La moraleja podría tener su origen en una máxima de Publilio Siro: ubi coepit ditem pauper imitari, perit. 
estas paráfrasis se ha realizado, sobre todo, atendiendo a criterios métricos ${ }^{9}$, a veces también, al léxico o al ritmo narrativo ${ }^{10}$, pero en nuestra opinión también hay que tener en cuenta la ideología, sobre todo cuando, como en este caso, se trata de ideas tan características y originales como la que estamos tratando.

Normalmente los autores de estas paráfrasis han alterado el contenido de los apólogos fedrianos, sobre todo en promitios y epimitios (infra, pp. 17-18), pero la perspectiva social, el conflicto interclasista, es todavía apreciable en ellos.

Entre las que nos han llegado bajo la autoría de Rómulo, merecen mencionarse El león y el ratón (22), donde se recomienda al poderoso perdonar al inocente «no sea que la casualidad le dé ocasión de vengarse» ${ }^{11}$; El león agradecido (51), en cuya moraleja se recomienda a los poderosos pagar el favor a los humildes; y El caballo orgulloso y el asno (53), cuyo epimitio advierte a todos ne quis in potentatu suo uellit aliquos ledere. Pero, sin duda, digna de especial mención es la fábula Los carneros y el matarife (76), que merece la pena trasladar aquí en su integridad por su contenido casi revolucionario:

Se hacinaban los carneros en compañía de los moruecos, cuando, viendo que el matarife pasaba entre ellos, hicieron como que no le veían. Pero aunque se daban cuenta de que uno de ellos era capturado, arrastrado y sacrificado por la mano mortífera del matarife, ni siquiera así tuvieron miedo, sino que imprudentemente entre sí decían: “a mí no me toca, a ti no te toca, dejemos que se lleve al que se lleva". Finalmente quedó uno solo. Cuando vio que era atrapado igual que los demás, dicen que habló así al matarife: "Merecidamente somos sacrificados uno por uno los que acabamos de ver esto, pues, cuando estábamos todos juntos y te vimos situado en medio del rebaño, no te matamos tras golpearte y despedazarte embistiéndote con nuestros cuernos".

Aunque la moraleja de Rómulo traslade el tema a los conflictos familiares, no hay duda de que este relato es un estímulo a la solidaridad de los oprimidos contra el opresor, expresado contrario sensu, censurando la insolidaridad de los animales que no supieron unirse para eliminar al matarife cuando tuvieron ocasión de hacerlo ${ }^{12}$; de manera idéntica a como lo hace el famoso poema Ellos vinieron de Martin Niemöller, común y erróneamente atribuido a Bertolt Brecht: «Cuando los nazis vinieron a buscar a los comunistas,/ guardé silencio,/ porque yo no era comunista./ Cuando encarcelaron a los socialdemócratas,/guardé silencio/.../Cuando finalmente vinieron a buscarme a mí,/ no había nadie más que pudiera protestar» ${ }^{13}$.

Parece, por lo referido hasta aquí, que los estudiosos mencionados al inicio del artículo tenían fundadas razones para considerar a Fedro un defensor de los humildes

\footnotetext{
Se trata de un asunto discutido: Zander (1921) propuso 30 fábulas, pero su reconstrucción fue contestada (Bertini-Gatti 1988). Sobre el tema, $c f$., también, Gatti 2004.

10 Mandruzzatto (1979) añadió en su edición dos fábulas más a las reconstruidas por Zander.

11 Cf. Innox, si peccat et rogat, oportet ut veniam accipiat, ne forte sit, ubi ulciscatur.

12 Al menos otras dos paráfrasis fedrianas censuran la insolidaridad junto con la falta de cautela. Los árboles proporcionaron un mango al hacha del leñador, sin percatarse de las consecuencias (64). Las aves no hicieron caso a la golondrina cuándo esta advirtió que el hombre sembraba lino para fabricar redes (24).

13 El poema fue recitado por primera vez en 1946 por el pastor protestante Martin Niemöller; su atribución a Bertolt Brecht, que todavía hoy es frecuente en los países de lengua castellana, tiene que ver con la semejanza ideológica de ambos autores y, sobre todo, porque fervientes seguidores del dramaturgo alemán lo recitaron como si fuera de su autoría.
} 
o un poeta proletario. Siendo esto así, resulta obligado plantearse tres cuestiones fundamentales: 1) ¿Hay coherencia real en el pensamiento de Fedro? Es decir, a pesar de las características del género fabulístico, con relatos aislados y diversos, ¿encontramos realmente una exposición coherente de sus ideas? Y, si esto así, ¿podemos saber hasta dónde llegan las ideas revolucionarias o rupturistas de Fedro? 2) ¿De dónde han surgido unas ideas tan originales? ¿Estaban en sus fuentes o en autores coetáneos? 3) ¿Qué recorrido ha tenido esta ideología en las colecciones fabulísticas posteriores, que tienen a Fedro como fuente? En las páginas que siguen vamos a intentar dar respuesta a estas cuestiones.

\section{Coherencia de ideas: justicia imposible y desigualdad inevitable.}

A pesar de las limitaciones que impone el género fabulístico, no hay duda de que las ideas que Fedro expresa en sus relatos, particularmente en los promitios y epimitios, están perfectamente conectadas. Lo hemos visto al comentar su posición ante el tema que estamos tratando, y es apreciable a propósito de otros temas, como su visión del fatum, la misoginia, la perspectiva sapiencial, el rechazo de las riquezas, etc. No hay que olvidar, además, que Fedro introduce cambios muy importantes en el género, sobre todo, al adoptar modos alejandrinos y neotéricos, que, de algún modo, contribuyen a la expresión, no solo de las reflexiones, sino también de los sentimientos del poeta (Gärtner 2007, Glautier 2009 y Cascón 2016). Es decir, la personalidad literaria de Fedro es inequívoca y lo suficientemente poderosa como para expresar sin dificultad y con coherencia las ideas que defiende, porque, además, piensa que esa es una de las funciones del género que cultiva ${ }^{14}$.

En el tema de la injusticia social Fedro parte de una convicción sólidamente asentada en sus apólogos: entre los hombres es imposible el triunfo de la justicia y esta imposibilidad se produce a su juicio por tres razones:

En primer lugar, en la persecución de sus intereses los hombres no dudan en comportarse injustamente. Lo hemos visto más arriba en fábulas como 1.1, 1.5, 1.17, donde el inocente cordero o la oveja, patiens iniuriae, sufren las consecuencias del malvado comportamiento del león, el lobo y el perro, que en la búsqueda de su beneficio no dudan en comportarse injustamente.

En segundo lugar, la ignorancia y estupidez de los hombres les lleva a cometer errores que facilitan el triunfo de la injusticia: así se demuestra en 5.5, donde el público aplaude al bufón que imita el berrido del cerdo, mientras que el campesino que esconde el marrano en su regazo es abucheado; el último verso expresa el desprecio por los juicios de la multitud: "en hic declarat, quales sitis iudices". También es apreciable en 1.14, donde la gente es engañada por el falso médico; Fedro dirige la moraleja del relato contra aquellos que alimentan la desvergüenza con su estupidez (Hoc pertinere uere ad illos dixerim/ quorum stultitia quaestus impudentiae est). Lo hemos visto también en esas paráfrasis fedrianas de Rómulo (24, 64 y 76), en las que las aves, los árboles o los carneros son incapaces de prever el daño que contra ellos preparan los malvados, allanando incluso el camino del enemigo. Pero hay otros muchos relatos, en los que el fabulista denuncia la estupidez humana: el stultus, opuesto

14 En el prólogo al libro III Fedro afirma que fue la esclavitud oprimida quien se sirvió del género para trasladar a las fábulas lo que no se atrevía a decir (vv. 34-36); cf. Cascón 2016, 90-91. 
al sollers o sapiens, es otro de los personajes frecuentes en su obra. De tal manera se califica al cuervo que se deja llevar por los halagos de la zorra (1.13); al águila y el jabalí, engañados por la gata salvaje (2.4); etc ${ }^{15}$. Podríamos decir que hay en la obra un impaciente rechazo hacia los personajes que carecen de inteligencia y se conducen con torpeza. En algunos apólogos, más que rechazo, lo que encontramos es un amargo lamento: el asno encuentra una lira que no sabe tocar (A.14); el pollo busca comida y encuentra una perla totalmente inútil para él (3.12); en el epimitio Fedro se dirige a aquellos que no entienden el contenido de sus fábulas: hoc illis narro, qui me non intellegunt.

En tercer lugar, la incapacidad natural del hombre para conocer la verdad impide el triunfo de la justicia. Significativa es en ese sentido la fábula 3.10, la más larga de las escritas por Fedro, donde los jueces (centumuiri), incapaces de resolver la acusación formulada contra una mujer, apelan a Augusto para que dicte sentencia.

Frente a esa desconfianza en la justicia humana, Fedro manifiesta su fe en la justicia divina: puede verse en 1.17, donde son los dioses quienes castigan al perjuro lobo, como se expresa en la sentencia final: Haec merces fraudis a superis datur. Es también perceptible en 4.26 , donde la providencia castiga al pugilista que se niega a pagar a Simónides el precio de su elogio (omnes scierunt numinum praesentiam/uati dedissem...), y en A.16, donde la intervención divina provoca el triunfo del pretendiente pobre (omnes fauorem comprobarunt caelitum).

Esta desconfianza en la capacidad del hombre para hacer justicia condiciona la visión que Fedro tiene de la sociedad. A partir de aquí, proyecta en sus fábulas un mundo en el que la desigualdad es norma y en el que se distinguen con claridad los culpables de esa situación de injusticia y los inocentes que padecen sus consecuencias. El primer culpable es, sin duda, el poderoso, que no duda en usar la fuerza para imponer su criterio, tal como hemos visto en las fábulas ya comentadas $(1.1,1.5$, $1.28,1.30$, etc.), representado por el león, el lobo, el águila, etc. El segundo culpable es la turba ignorans o imprudens, que contribuye a la situación por su torpeza o incapacidad; recordemos las fábulas 1.14, 3.10, 5.5 y alguna otra, como 4.5, donde la sabiduría de Esopo se opone a la imprudentia de la turba, incapaz de interpretar un testamento (Ita quod multorum fugit imprudentiam/ unius hominis repperit sollertia). Aunque la culpabilidad de esta multitud ignorante no es en el conjunto de la obra equiparable a la del poderoso, ambos grupos sociales provocan la existencia del humilis innocens, víctima de la situación, representado, como hemos visto, por el agnus de 1.1, la ouis (patiens iniuriae) de 1.5, las ranas de 1.30, etc.

\section{La propuesta de Fedro}

¿Qué alternativas propone Fedro ante esta situación que acabamos de describir? Es difícil dar una respuesta certera, pero, a nuestro juicio, no hay en sus fábulas ideas revolucionarias tendentes a corregir dicha situación. Tal vez considera inalcanzable para la voluntad humana un cambio que va contra las leyes del fatum, en cuya omnipotencia parece creer ciegamente ${ }^{16}$. Sus ideas a favor del humilis parten del presu-

15 En general el stultus se identifica con el crédulo (1.23, 2.4, 1.14), el incauto (1.9), el vanidoso (1.13), el insensato (1.20) y tiene un gran protagonismo en la obra.

16 Son muchas las ocasiones en que los protagonistas de sus fábulas deploran su amargo destino y frecuentes los 
puesto de que la situación de este es insuperable. Incluso parece censurar la conducta del que intenta ascender en la escala social, como en 1.27, con el ejemplo del perro que se apoderó de un tesoro; el fabulista dirige el relato contra qui humiles nati dici locupletes student. O en 1.24, con el de la rana que intentando imitar al buey reventó (inops potentem dum uult imitari, perit). En el promitio de 2.5 denuncia también a los aduladores que pretenden ascender sin hacer nada y que, según nos cuenta, eran legión en Roma (Est ardalionum quaedam Romae natio,/.../sibi molesta et aliis odiosissima/ emendare si tamen possum...).

Por tanto, si nuestro autor niega al humilis la posibilidad de cambio, ¿de qué modo puede afrontar su injusta situación? Primero, considerando las ventajas de su estado, sin envidiar al rico o al poderoso, expuestos a situaciones de riesgo fácilmente evitables para el humilde, tal como hemos visto en 4.6 (minuta plebs facili praesidio latet) o en 1.15 (In principatu commutando saepius/nihil.../mutant pauperes). En segundo lugar, confiando en la intervención providencial y justiciera de los dioses, como hemos constatado en $1.17 ; 4.26$, etc. Por último, y este consejo quizá sea el más interesante, utilizando la sollertia en contra del poderoso, como veíamos en 1.28, donde la zorra consigue con ingenio recuperar las crías que el águila le había arrebatado; recordemos la moraleja: quamuis sublimes debent humiles metuere...; tal consejo es perceptible también, pero en sentido contrario, en las paráfrasis medievales donde se critica la actitud torpe y falta de cautela de los humildes, por no prever las asechanzas de los poderosos (Romulo, 24, 64, 76, etc.).

Sin embargo, esa rebeldía a la que Fedro instiga no puede ser nunca irreflexiva. Por ello en A.20 Esopo desaconseja la huída a un esclavo maltratado por su amo, ya que con ello únicamente conseguiría aumentar sus desgracias: "Aunque no has hecho nada malo, sufres estas calamidades que me cuentas; ¿qué te ocurriría si cometieras alguna falta?, ¿qué crees que te tocaría padecer?» (vv.16-18). El fabulista no reprueba la acción del esclavo, sino las consecuencias negativas que esta puede entrañar para el propio interesado (Bajoni, 1999). Es necesario, por tanto, servirse de la inteligencia, como hizo la esclavitud oprimida, cuando, según Fedro, inventó el género fabulístico para desde su débil posición, expresar las ideas que no se atrevía a manifestar abiertamente (Cf. 3. prol. 33-37: Nunc, fabularum cur sit inuentum genus, / breui docebo. Seruitus obnoxia, quia quae uolebat non audebat dicere,/ affectus proprios in fabellas transtulit,/ calumniamque fictis elusit iocis.).

Así pues, coincidimos con Nøjgaard cuando señala que en Fedro falta un espíritu revolucionario de clase que instigue claramente a la revuelta contra el poderoso, una posición coherente con su aparente convencimiento de que tal empresa no tendría éxito, ya que el humilde no puede cambiar su injusta situación. Ahora bien, no podemos admitir que el consejo de Fedro sea, únicamente, resignarse ante tal situación, pues, como hemos visto, mediante el empleo de la sollertia, el débil puede en caso concretos sobreponerse al poderoso.

Está claro, por otra parte, que Fedro no defiende la abolición de la esclavitud, pues, aunque en el prólogo al libro tercero, dice, como hemos visto, que el género fue inventado por la seruitus obnoxia para poder expresar sus ideas, sin embargo, a lo largo de la obra se habla genéricamente de humiles y de innocentes, pero no hay expresas alusiones a los esclavos, es más, el esclavo atriense de 2.5 o el siervo im-

pasajes en que el propio fabulista explica su importancia en la vida de los hombres (cf. 4.1, 4.11, 5.6, etc.). Es, desde luego, un pensamiento muy estoico: «'lo que es' es correcto por el hecho de ser». 
portuno de A.27 son ejemplos de personajes criticados por el autor. Dentro de este estamento también existía desigualdad social y los más 'privilegiados' aceptaban su situación. El término humiles, tal como lo emplea Fedro, hace pensar en una ideología que pretende defender a las personas más desfavorecidas, las clases bajas de la sociedad libre y la mayoría de los esclavos, pero no se observan rasgos de 'abolicionismo’ en sus fábulas.

\section{EI tema en las colecciones fabulísticas antiguas}

La colección de fábulas de Fedro es la más antigua de las conservadas en latín o en griego. De modo que no podemos saber con seguridad si en algunas de las colecciones que Fedro pudo manejar para la composición de su obra el tema tenía un tratamiento similar al que encontramos en nuestro fabulista. Sin embargo, si así hubiera sido, es lógico suponer que hubiese dejado algún rastro en las otras colecciones de época clásica, particularmente en la Augustana (lo que llamamos Esopo) por tratarse de una colección anónima y en prosa donde se recogen apólogos de muy diversa procedencia, pero también en el griego Babrio o en el latino Aviano.

En las fábulas conservadas más antiguas, fuera de colección, ya aparecen algunos de los principios que vamos a comentar aquí, sobre todo en lo que se refiere a la prevención contra el poder establecido y a la necesidad de aceptar el orden jerárquico, lejos del tratamiento reivindicativo de Fedro, que hemos visto más arriba ${ }^{17}$.

Repasemos cómo aparece en cada una de estas obras, empezando por Babrio, el más antiguo después de Fedro ${ }^{18}$.

Las ideas de Babrio no coinciden con las de Fedro: no existe un claro rechazo del poderoso o de la turba ignorante ni se percibe una defensa del humilde ante su injusta situación social. En la oposición fuerte/débil, frecuente en toda la fabulística y desde luego en sus apólogos, resulta más difícil descubrir el enfrentamiento entre poderosos y humildes que con toda claridad observamos en Fedro. Únicamente, en 4 , donde el pez pequeño evita mejor los peligros que el grande, y en 112, donde el ratón se muestra superior al toro, evocamos aquellas fábulas fedrianas $(1.15 ; 4.6)$, en las que se aludía a las ventajas que tiene la minuta plebs en los momentos de riesgo; «A veces es una ventaja el ser pequeño y humilde», dice la moraleja ${ }^{19}$.

A partir de otras fábulas de Babrio podríamos conjeturar, con cierta base, una defensa por su parte de la estratificación social, a pesar de la desigualdad que comporta. En 128 la oveja, que proporciona al pastor alimento y vestido, se queja de no recibir nada a cambio mientras el perro está bien cuidado; la réplica final defiende esta situación, ya que el perro, que rechaza a ladrones y lobos, realiza una función más elevada. En 134 se critica a la cola de la serpiente por pretender suplantar a la cabeza en la dirección de la marcha; el relato muestra el fracaso de la innovación. En 82, con el ejemplo del león ofendido por el ratón, Babrio aconseja en la moraleja «no tolerar la burla de los inferiores». En 36, con el argumento de la encina y la caña,

17 Cf. Mordeglia (2014, 119-122) comenta fábulas de Hesíodo, Arquíloco, Aristóteles, etc., de claro tono conservador todas ellas, donde se evidencia las malas consecuencias que tiene para el débil enfrentarse al poderoso.

18 Sobre la cronología de estas colecciones, cf. Rodríguez Adrados 1979, 80, 114 y 133.

19 En la traducción de las fábulas de Esopo y Babrio seguimos la edición de Bádenas y López Facal, 1978, Madrid, Gredos. 
recomienda no enfrentarse a los poderosos: «la fabula nos revela que no hay que luchar contra los poderosos, sino ceder» ${ }^{20}$.

Estos relatos vienen a demostrar el distinto tratamiento del tema en esta colección $^{21}$. Como muy bien señaló Nøjgaard, la fábula babriana intenta demostrar la necesidad de aceptar el orden social, Babrio parece opinar que el poderoso ocupa con justicia su rango y está autorizado a oprimir al débil. Este solo puede aspirar a la clemencia del poderoso ${ }^{22}$.

En la Augustana, como en Babrio, tampoco aparece la denuncia de la injusticia social. El rechazo de la actitud malvada del potens o la defensa sentida del humilis, propias del fabulista latino, no tienen correlato en esta colección. Sí encontramos, sin embargo, algunas de las ideas que hemos visto formuladas anteriormente en Fedro o Babrio. La imposibilidad de que el humilde pueda igualarse al poderoso (cf. Fedro, 1.24) se muestra en 2 , donde el grajo no puede imitar al águila. La convicción de que es el débil quien padece las consecuencias del enfrentamiento entre los poderosos (cf. Fedro, 1.30) parece subyacer en 197, donde los ratones que presencian la disputa entre la serpiente y la comadreja se ven sorprendidos por el ataque de ambos animales. Hay dos fábulas en las que podemos percibir la defensa del inmovilismo social y del orden establecido que hemos apreciado en Babrio. En 179, con el ejemplo del asno que pide a Zeus cambiar de amo y se encuentra en peor situación, se alude a los sirvientes, «que añoran a sus primeros amos, cuando tienen la experiencia de otros nuevos". En 153, a propósito del relato de las ovejas que expulsan a los perros para pactar con los lobos, se reprueba la actitud de los estados que abandonan a sus jefes. La recomendación al poderoso de comportarse conmiserativamente con el humilde se percibe con claridad en 150 o 235, en cuyo epimitio se recuerda que los más insignificantes pueden proporcionar grandes beneficios a sus benefactores.

Parece claro, pues, que en Esopo, como ocurría en Babrio, no hay interés en denunciar la injusticia social. Hallamos incluso fábulas en las que el fuerte se impone injustamente al débil, sin que tal acción sea criticada (cf. 4 y 119) o apólogos en los que, por el contrario, la habilidad del pequeño supera el poderío del grande (131), sin que las moralejas aludan, siquiera alegóricamente, a la estratificación social. Tal vez, porque, como afirma García Gual $(1983,319)$, la moral esópica no pretende decir cómo debería ser el mundo, sino cómo es este ${ }^{23}$.

En la colección de fábulas de Aviano el tema tampoco tiene la presencia y la importancia que apreciamos en Fedro. El conflicto social no aparece en Aviano, aunque encontramos en su obra principios que hemos visto en otras colecciones y en algunas de sus fábulas lo que parecen ser vestigios del ideario fedriano.

Por ejemplo, en 11, donde la olla de barro rehúye la compañía de la olla de bronce al ser ambas arrastradas por la corriente del río; el argumento sirve a Aviano para

20 Palabras parecidas encontramos en Fedro A 26: “despicio inermes, eadem cedo fortibus", pero tales palabras están puestas en boca de una corneja a la que nuestro fabulista tacha de odiosa.

21 Para entender mejor la notable diferencia que media entre los dos fabulistas es necesario tener presente que Babrio dedicó sus fábulas a un príncipe, «al hijo del rey Alejandro», según expresa en las primeras líneas de su prólogo al libro II.

22 Nøjgaard (1967, 353-355) resume la concepción babriana de las relaciones sociales indicando cómo para este fabulista el poderoso ocupa con justicia su rango y está autorizado a oprimir al débil, tan solo es deseable que se comporte con dulzura; por su parte, el humilde, en su relación con el poderoso, únicamente puede esperar la clemencia de este.

23 Gasparov (1968) subraya, por su parte, el profundo conservadurismo que late en los apólogos de la Augustana. 
afirmar que no hay lealtad entre el pequeño y el poderoso (v. 10: quia nulla breui est cum meliore fides), haciéndonos recordar el promitio de Fedro 1.5: numquam est fidelis cum potente societas. Aviano sustituye la oposición potens/ humilis de Fedro por la menos comprometida melior/breuis.

El tema de 41 incide en la idea, ya vista en anteriores colecciones, de que el humilde no debe imitar al poderoso (cf. Fedro 1.24 y Esopo 2); es la fábula de la olla de arcilla que se vanagloria ante la nube de ser un ánfora; en la moraleja, Aviano desancoseja al miser lamentarse de su destino ante el nobilis.

En 31, versión de Babrio 112, se muestra con el argumento del ratón y el buey, las ventajas que en ocasiones comporta ser pequeño; tal como se indica en el epimitio: «Aprende... cómo la gente pequeña hace lo que quiere hacer».

En 35, a propósito del apólogo de los hijos de la mona, que pierde al hijo que más quiere y conserva al que aborrece, Aviano señala en el epimitio cómo las circunstancias de la vida pueden hacer que la suerte del humilis cambie (ordine uerso/ spes humiles rursus in meliora refert). Es significativo que en las versiones de este apólogo de Babrio (35) y Esopo (218) no encontremos ninguna alusión a la suerte del humilis.

Así pues, la revisión de estas tres colecciones nos ha permitido apreciar la existencia de una serie de principios ético-sociales, que, podríamos decir, forman parte de una moral inherente al género, lo que La Penna $(1961,518)$ llama la moral esópica, y que, formulados de distinta forma, aparecen en todas o en la mayoría de estas colecciones. Mencionemos algunos de estos principios: el humilde no puede cambiar su situación; el humilde no debe imitar al poderoso; la recóndita posición del humilde en la escala social puede ser ventajosa en algunas ocasiones; la asociación con el poderoso nunca es segura; los humildes suelen padecer las consecuencias de las disputas entre los poderosos.

Sin embargo, algunos de los principios que parecen pertenecer a la moral esópica no han sido admitidos por Fedro, como la defensa de la estratificación social o la recomendación al poderoso de un comportamiento conmiserativo con el humilde que hemos visto en algunas fábulas de Babrio, Esopo o Aviano. Inversamente, no aparecen en estos autores las reflexiones fundamentales de Fedro sobre la justicia social: rechazo del poderoso; exhortación a la solidaridad de los humildes y eventualmente a la venganza. García Gual $(1983,318)$ señala cómo en la ideología esópica la astucia, que personifica la zorra, es una arma recomendada para la rebelión. Sin embargo, la perspectiva de Fedro es distinta a la de las otras colecciones, sobre todo, porque, la oposición humildes/poderosos de Fedro es sustituida por la oposición fuerte/débil. Es decir, la perspectiva de Fedro es mucho más ideológica. Mientras la Augustana da consejos prácticos para la vida, Fedro reivindica la situación injusta de los más humildes.

Además, en la comparación concreta con cada uno de esos autores percibimos singulares disparidades y alguna coincidencia llamativa. Por una parte, hemos advertido cómo Babrio dirige algunos de sus consejos al poderoso (cf. 107, 82), lo que resulta particularmente alejado de la propuesta fedriana, que, como hemos visto, se dirige siempre al humilde, para criticar su falta de cautela y agilizar su inteligencia. Por otra, hemos señalados ciertos paralelismos entre Aviano y nuestro fabulista, difícilmente explicables si no se acepta la influencia directa del segundo en el primero (Gaide 1980, 43-45 y Cascón 2005, 226-228).

El análisis de las diferentes versiones de un mismo argumento sirve para probar algunas de las conclusiones que acabamos de apuntar. El conocido argumento del re- 
parto del león lo encontramos en F.1.5; B.67 y E.149; las moralejas descubren intenciones diferentes (Moller Jensen 2004): la Augustana se limita a describir cómo los hombres se vuelven comedidos ante el infortunio y Babrio y Fedro desaconsejan la alianza con el poderoso, pero mientras éste lo hace atacando al potens, como grupo malvado, improbus, aquel se limita a dar un consejo práctico («no te alíes para ningún asunto con un hombre más poderoso que tú»), descargado de las valoraciones ético-sociales que se aprecian en Fedro.

La fábula de «Los ratones y las comadrejas" la encontramos en F. 4.6; B.31 y E. 165. Aunque las narraciones son muy similares, los epimitios expresan ideas diferentes; Esopo rechaza el ansia de gloria como motivo de desgracia; Babrio y Fedro constatan que el personaje menos relevante vive más aseguro, pero mientras Babrio lo formula en abstracto y de forma teórica (cf. «para mantenerse lejos del peligro es mejor la mediocridad que la brillantez»), Fedro se apega a la realidad social, explicando cómo en las desgracias que sufren los pueblos la minuta plebs está más segura que los principes.

F.1.28 se corresponde con E.1. Los argumentos varían respondiendo a la intención que cada fabulista pretende. En la fábula esópica hay una violación religiosa del vínculo de la amistad que es castigada por los dioses, mientras que el relato fedriano es un conflicto entre humildes y poderosos que se resuelve con la actuación inteligente del débil para rescatar a sus crías.

El argumento del sapo que pretendió igualarse al buey lo hallamos en F.1.24 y B.28. En Babrio la narración, contada con gracia, carece de moraleja, mientras en la versión fedriana se alude al conflicto entre los estratos sociales, al constatar la imposibilidad de que el inops iguale al potens.

Así pues, parece claro que Fedro es en este tema original respecto a la tradición fabulística antigua y, como en otros aspectos, se ha mostrado renovador del género ${ }^{24}$. Comparte principios de la moral esópica tradicional y en algunas de sus fábulas se percibe la crítica contra el poder establecido de los estratos cínicos, pero su ataque al poderoso y la denuncia de la injusticia social es, como decimos, absolutamente original. Siendo esto así, es obligado plantearse de nuevo la cuestión que mencionábamos más arriba: ¿De dónde han podido surgir estas ideas sobre la injusticia social tan singulares en el Mundo clásico?

\section{El origen de las ideas de Fedro}

Desde el luego, el conocimiento de las circunstancias de su vida resulta útil para entender esa forma pensar ${ }^{25}$. Aunque recientemente se haya puesto en duda que nuestro fabulista fuese realmente liberto de Augusto e incluso su conocida calamitas llegue a contemplarse como parte de un deliberado programa literario (Mattiaci 2014) o incluso como enmascaramiento de su personalidad aristocrática (Champlin 2005), parece muy difícil refutar que Fedro padeció una acusación a su juicio injusta que le acarreó graves problemas. Además de estas vicisitudes, mayoritariamente aceptadas por los especialistas, es probable que fuera abandonado por su madre y que sufriera

24 Por ejemplo, la introducción del componente autobiográfico, al estilo de los neotéricos, es una innovación dentro del género sin correlato en otras colecciones, cf. Cascón 2016, 96-98.

25 Un resumen de las hipótesis más importantes sobre su vida puede verse en Cascón 2005, 16-24. 
la esclavitud ${ }^{26}$; por otra parte, si alguna vez conoció el éxito literario, este se produjo tardíamente (Cascón 2016, 85). Todo ello parece indicar que Fedro fue un individuo humilis e innocens, que padeció la injusticia en su propia carne. El propio autor confiesa su condición plebeya, al evocar el famoso verso de Ennio: «Yo, cuando era niño, hace ya tiempo, leí una frase: "murmurar en público es un sacrilegio para un plebeyo", mientras conserve la cordura lo recordaré muy bien $\rangle^{27}$. La cita es importante porque confirma la condición humilde del poeta y, además, permite corroborar la convicción fedriana de que las injusticias que padecen los humildes no tienen solución. No podrá olvidar la frase porque su contenido tendrá siempre vigencia (Gärtner 2011 y Lelli 2001).

Resulta inútil buscar en la obra de sus coetáneos latinos coincidencias en el tratamiento del tema. Para él solo existen dos clases sociales radicalmente enfrentadas: los humildes y los poderosos; poco le importan los diferentes ordines en que estos se dividan; ni senadores ni équites ni ningún otro grupo social tienen una personalidad definida en su obra. Su perspectiva está muy alejada de otros escritores latinos, comprometidos con un ordo o una factio determinada.

Sin embargo, el griego Plutarco y el latino Floro nos han conservado un discurso de Tiberio Graco en defensa de la plebe, que se ha hecho famoso por las ideas que contiene, sorprendentes palabras para la época en que fueron pronunciadas. El propio Plutarco las elogia en su biografía:

Tiberio, luchando por una causa hermosa y justa con un discurso capaz de embellecer incluso acciones menos nobles, era impresionante e invencible cuando hablaba en defensa de los pobres con el pueblo puesto en pie y rodeando la tribuna: "que incluso las fieras que habitan Italia tienen su guarida y cada una de ellas tiene un refugio, una cueva; en cambio para los que luchan y mueren por Italia, sólo hay aire y luz, nada más, y sin casa ni un lugar seguro, vagan con sus hijos y mujeres; y los generales engañan a los soldados en las batallas, animándolos a expulsar a los enemigos para defender tumbas y santuarios, pues ninguno de entre tantos romanos tiene ni altar familiar ni lugar de culto de sus antepasados, sino que combaten y mueren por el lujo y la opulencia ajenas hombres que reciben el nombre de dueños del mundo, pero no tienen ni un terrón suyo". Ninguno de los opositores plantó cara a unas palabras que, nacidas de un ánimo elevado y un sentimiento sincero, caían sobre un pueblo que se entusiasmaba y sublevaba con ellas (Plut.Tib. 9. 4-6) ${ }^{28}$.

En este discurso sí encontramos denuncia de la injusticia social, vilipendio de los poderosos, defensa de los humildes y el mismo tono sentido que se aprecia en las fábulas de Fedro. Este discurso de Tiberio Graco, comentado muchas veces por su carácter excepcional en las letras latinas, es un argumento utilizado siempre por aquellos que defienden la sinceridad en las propuestas de igualdad social de los hermanos Graco. En ese sentido, deben recordarse: su lex agraria, que intentaba una

26 Sobre este punto, uid., entre otros, Marchesi 1923, 53; Della Cortte 1939, 139-140; De Lorenzi 1955, 35-36.

27 ego, quondam legi quam puer sententiam/ "Palam muttire plebeio piaculum est", dum sanitas constabit, pulchre meminero (3. ep. 33-35). Se trata de un verso de una tragedia perdida de Ennio titulada Télefo (Frag. 331 Valhen).

28 Citamos la traducción al español de Alcalde y Gonzalez, 2010, Madrid, Gredos. También Floro (2.2.1-4) se refiere a este discurso de Tiberio en su Epitome de la Historia de Roma. 
distribución más justa de la tierra; su lex frumentaria, que contemplaba subvencionar el trigo para los más necesitados, y sus proyectos de extensión de la ciudadanía romana, entre otras proposiciones de ley claramente progresistas desde el punto de vista social. Cuando se ha tratado de indagar cuáles son las raíces ideológicas de este programa, siempre aparece el nombre de Blosio de Cumas, un estoico preceptor de Tiberio y Gayo Graco, al que Plutarco considera instigador del programa político de los dos hermanos.

Pero Tiberio, nada más ser nombrado tribuno de la plebe, se aplicó a esta tarea a instancias, según cuenta la mayoría, del rétor Diófanes y del filósofo Blosio. De estos, Diófanes era un exiliado de Mitilene, el otro era de la misma Italia, de $\mathrm{Cu}-$ mas, amigo íntimo en la Ciudad de Antípatro de Tarso, y que había tenido el honor de que este le dedicase sus escritos filosóficos (Ibid. 8,6).

Según distintos autores, Blosio pertenecería a la línea más radical del estoicismo, que preconizaba la igualdad social, sin detenerse siquiera ante la propiedad privada (Nicolet 1965). El profesor Solana Dueso $(2015,84-92)$ en un reciente artículo sostiene que, se habrían creado en la escuela del Pórtico dos corrientes, una, más utilitarista y defensora de la propiedad privada, que sostendrían personalidades como Perseo, Diógenes de Babilonia y Panecio de Rodas; otra, más radical, y defensora de la igualdad social, que estaría representada por Esfero, consejero de Agis y Cleomenes en la revuelta social espartana, Antípatro de Tarso, que en la obra de Cicerón aparece siempre como el máximo defensor de lo honesto frente a lo útil ${ }^{29}$, y Blosio de Cumas, que además de impulsar junto a los Graco reformas parecidas a las de Agis y Cleomenes, fue promotor de la República social de Aristarco en el reino de Pérgamo ${ }^{30}$.

Muy probablemente Fedro continúa esta línea del estoicismo. Es evidente que la filosofía estoica influyó de forma determinante en sus ideas, como lo demuestra, su perspectiva sapiencial (el sapiens, representado sobre todo por Esopo, se opone al stultus y a la turba ignorans), su rechazo radical de las riquezas, su convicción de que el destino es omnipotente, su creencia en una divinidad trascendente, etc. Fedro, que siempre se muestra apasionado en la defensa de sus principios éticos, eligió en el tema que nos ocupa la corriente más radical del estoicismo. Esa línea de pensamiento poco tiene que ver con algunos principios cínicos, presentes en la tradición fabulística, contrarios al poder político tuviera este la forma que fuese (Rodríguez Adrados 1987; Mañas, 1998) ${ }^{31}$. Las fábulas de Fedro demuestran que esa corriente estoica que defendía la igualdad social y la ciudad universal tenía vigencia en la

29 Cicerón aborda el conflicto entre lo útil y lo honesto en el libro tercero de su Tratado sobre los deberes. Allí menciona a Antípatro como el defensor de lo honestum por encima de cualquier consideración, frente a Diógenes de Babilonia y Panecio que eludían tal conflicto, cf. Solana 2015, 86-89.

30 Aristónico, hijo de Eumenes II, intentó recuperar el reino de Pérgamo que Atalo III había dejado en herencia a los romanos. Apoyado por esclavos y desfavorecidos de la fortuna obtuvo algunas victorias sobre los romanos, pero fue derrotado en el 129 a. C. Blosio marchó a su corte después de la muerte de Tiberio Graco y allí se suicidó, como refiere Plutarco (Tib. 20, 7).

31 En la obra de Fedro encontramos vestigios del influjo de la filosofía cínica en el género, pero algunas de sus ideas más características (creencia en la providencia divina y el fatum omnipotente, defensa de la familia, beneficios de la educación benevolente, etc.) son claramente de raíz estoica y contrarias a la propuesta de vida del cínico. 
sociedad romana y llegaría desde luego hasta Marco Aurelio, en cuyas Meditaciones podemos leer pasajes como el siguiente:

De mi hermano Severo [aprendí]: el amor a la familia, a la verdad y a la justicia...; el haber concebido la idea de una constitución basada en la igualdad ante la ley, regida por la equidad y la libertad de expresión igual para todos, y de una realeza que honra y respeta, por encima de todo, la libertad de sus súbditos ${ }^{32}$.

Evidentemente, esta forma de pensar parece haber sido minoritaria, al menos entre las clases acomodadas y más cultas. Los populares que siguieron a los Graco (Mario, César, Salustio, etc.) fueron alterando paulatinamente su discurso, haciéndolo más demagógico. Las ideas de Fedro se confundieron en medio de otros principios éticos más convencionales, 'escondidas', además, en el envoltorio de un género donde las intenciones ideológicas pueden pasar más desapercibidas. Pero parece claro que las ideas estoicas de igualdad y justicia social se mantuvieron hasta Marco Aurelio y Epicteto y, sin duda, influyeron en otras doctrinas filosóficas y religiosas del Imperio Romano.

Veamos ahora cómo fueron asumidas las ideas de Fedro por la tradición fabulística posterior.

\section{El tema en los fabulistas continuadores de Fedro}

Como era de esperar, este tema ha dejado huella en las colecciones fabulísticas medievales anónimas o semianónimas, codex Wissemburguensis, codex Ademari o Romulus $^{33}$, continuadoras de Fedro y, en general, muy dependientes de sus fábulas en estilo y contenido. Sin embargo, hallamos ya cambios notables, sobre todo en los promitios y epimitios. Algunos los hemos comentado ya más arriba al hablar de las fábulas del 'Fedro perdido' (supra, p. 3), pero son muy apreciables en aquellas versiones de los relatos fedrianos donde más claramente se aborda el enfrentamiento entre humildes y poderosos. Por ejemplo, en las versiones de I 28 (Ad. 14; Wiss. II 2 y Rom. 16) se critica el comportamiento abusivo del poderoso, pero en ninguna de ellas encontramos la incitación a la venganza inteligente que veíamos en la fábula de Fedro (Caputi 1998). Las versiones de Fedro 2.6 del codex Wissemburguensis (2.5) y Romulus (17) reprueban la conducta del maleficus consiliator, pero no la del poderoso. Las distintas adaptaciones de Fedro 1.5 han mantenido la advertencia fedriana que desaconseja la alianza con el poderoso (Ademar 9 y Rómulo 8), pero la identificación entre improbus y potens que veíamos en el fabulista romano solo se mantiene en el codex Wiss ${ }^{34}$. No obstante, está claro que en estas colecciones, sumamente deudoras de su fuente, el conflicto entre humildes y poderosos sigue estando vigente, aunque de forma mucho más matizada y, según parece, poco buscada ${ }^{35}$.

\footnotetext{
Marco Aurelio, 1, 14. Citamos la traducción de R. Bach, 1990, Madrid, Gredos.

33 Para la comprensión del origen y la interdependencia de esas tres colecciones, remitimos a las introducciones de Thiele 1910, Cascón 2005, 291-296 y Mordeglia 2016.

Cf. sic totam praedam solus improbus abstulit (I 7).

35 Hay otra fábula, Leo senex et vulpis (Rómulo 86, Ademar 59) que por su estilo narrativo y por el tema, también podría incluirse entre las fábulas perdidas. Es el argumento de la zorra que se niega a entrar en la cueva del león
} 
Avanzando en el tiempo, si nos fijamos en la colección de Vincent de Beauvais, observamos algunos cambios respecto a su modelo Romulus, que desvirtúan un poco más las ideas de Fedro. En su versión de la fábula Vacca, capella, ouis et leo (4), el claro ataque, que vimos en Fedro 1.5 y en menor medida en Rómulo 8, se vuelve contra los que incautamente se asocian con los poderosos (Contra illos qui incaute sociantur potentibus), sin rastro del ataque al potens. En 16, Rana rupta et bos, no se muestra la imposibilidad real de que el inops pueda igualarse al potens, como en F. 1.24 o Rom. 50 («si un pobre quiere imitar al poderoso, revienta»), sino que reprueba el comportamiento del que, siendo pobre, es soberbio (cf. Contra pauperem superbum).

El tono e incluso los términos empleados por Walter el Inglés en sus versiones de algunas de las fábulas hasta aquí comentadas, se alejan notablemente de Fedro y suponen, respecto a Rómulo, un paso más en la desvirtuación del ideario fédriano. En De leone et mure (18) se amonesta al poderoso con el tono paternalista que veíamos en Babrio: no se debe despreciar al que es capaz de hacer cosas pequeñas, pero alguna vez puede ser útil: tu, qui summa potes, ne despice parua potentem,/ nam prodesse potest... Una moraleja parecida a la que encontramos en De vulpe et Aquila (13), donde se habla de que el maior no sea obstáculo para el minor, en un intento de desideologizar el principio fedriano. En realidad, tanto Walter como Beauvais se alejan un poco más de la óptica de Fedro, pues, hay cambios sutiles en el tono, los términos empleados o la intención de los epimitios, que varían sustancialmente el pensamiento de Fedro, en un proceso que se va haciendo menos ideológico y más moral, sin duda por el influjo del pensamiento cristiano.

$\mathrm{Si}$ ahora revisamos las colecciones fabulísticas modernas, a las que Fedro ha servido de base, nos encontramos con una situación bastante parecida. La Fontaine modifica las versiones del fabulista romano, nublando o trivializando las contundentes denuncias de Fedro ${ }^{36}$. Veamos algunos ejemplos: La versión de La Fontaine del relato de El lobo y el cordero (1.10) omite el contundente epimitio de Fedro 1.1 contra aquellos que «con fingidos pretextos oprimen a los inocentes». En su versión de la fábula 'del reparto del león' (1.6) no hay moraleja que desaconseje la alianza con el poderoso ni la identificación entre este y el malvado de Fedro 1.5. Su versión del relato de El asno al pastor viejo (6.8) omite el promitio de Fedro 1.15, en el que se alude a los cambios de gobierno y a los pobres. La Fontaine no escribió una versión de La zorra y el águila, un apólogo en el que Fedro (1.28) incitaba a la venganza inteligente contra el poderoso. Con independencia de estos cambios o supresiones, el fabulista francés introduce un tono cómico en sus narraciones que también contribuye a minimizar las ideas de Fedro; por ejemplo su versión de la Rana que quiso ser como el buey (1.3) critica a aquellos que intentan equipararse a los que están más altos en la escala social: «Tout Bourgeois veut bâtir comme les grands Seigneurs/.../ Tout Marquis veut avoir des pages», muy lejos del promitio de Fedro (1.24) que constataba la incapacidad del pobre para igualarse al poderoso.

Samaniego, cuya dependencia de Fedro hemos demostrado en artículos anteriores (Cascón 1986 y 2002), elude hacer versiones de aquellas fábulas de Fedro en las que más claramente se perciben sus ataques al poderoso, como $1.1 ; 1.5 ; 1.28 ; 1.30$;

que fingía estar enfermo; las moralejas en este caso sí parecen haber conservado la intención fedriana: In domum potentis facile est intrare, exire autem iam tardum est.

36 Sobre el influjo de Fedro en La Fontaine y la libertad de adaptación de este último, cf. Herrmann (1963-1964) y Waltz (1954). 
etc.; en otras, que sí han sido adaptadas por el fabulista vasco, encontramos cambios significativos. Por ejemplo, en 2.3, El asno sesudo, imitación de Fedro 1.15, Samaniego no ha recogido el promitio fedriano de matiz político; en su lugar, se lee esta moraleja «Nada teme perder quien nada tiene».

Hay, no obstante, otros relatos que no están en Fedro en los que Samaniego señala la injusta situación del humilde $(3.2 ; 9.19 ; 1.5)$, pero lo hace en un tono humorístico que atenúa la crítica, en contraste con la seriedad de Fedro. Por ejemplo, en la moraleja de 3.2: «Te juzgarán virtuoso, /si eres, aunque perverso, poderoso;/ y aunque bueno, por malo detestable,/ cuando te miren pobre y miserable».

Son sólo algunos ejemplos de los cambios ideológicos que pueden apreciarse entre ambas obras. En el caso de Samaniego, como en el de La Fontaine, las intenciones literarias están muy por encima de las ideológicas. La despreocupación o la falta de interés por el tema es más que evidente.

Se puede afirmar, por tanto, que el tema de la injusticia social, tal como aparecía en la obra de Fedro, se ha ido diluyendo paulatinamente en las versiones de sus fábulas que han escrito sus continuadores. Todavía se aprecia algo de la relevancia que tenía en su obra en las colecciones anónimas latinas medievales, pero en las más tardías y de autor reconocido, el enfrentamiento entre humiles et potentes tiene escasa presencia y a veces incluso un enfoque contrario a las ideas de Fedro.

\section{Conclusiones}

Fedro denuncia en sus fábulas de forma insistente las injusticias que padecen los humildes y el comportamiento malvado de los poderosos. Esta denuncia de la injusticia social es apreciable tanto en las fábulas que nos han llegado con su autoría como en el llamado "Fedro perdido", hasta el punto de que la presencia de estas ideas en las paráfrasis debe ser tenida en cuenta a la hora de considerar su atribución a Fedro.

A pesar de las dificultades que impone el género, Fedro formula una propuesta coherente, que implica no solo la denuncia del comportamiento injusto de los poderosos sino también la culpabilidad de la turba ignorante, incapaz de hacer justicia. Ambos grupos sociales provocan la presencia del humilis innocens, que no puede esperar un cambio radical en su situación, pero tampoco ha de resignarse; debe actuar con cautela, esperar la intervención providencial de los dioses y eventualmente utilizar la sollertia para vengarse del poderoso. Pero la rebeldía que propone Fedro nunca ha de ser irreflexiva. Frente a la esclavitud no es abolicionista. No defiende al esclavo sino al humilde.

Estas ideas no tienen parangón en la tradición fabulística; es más, en Babrio o en la Augustana lo que encontramos son propuestas mucho más conservadoras: defensa de la estratificación social, exhortación al débil de conformidad con su situación y al fuerte de clemencia con el débil. No parece, por tanto, probable que Fedro haya asumido en este tema ideas que se encontraran en colecciones fabulísticas que le sirvieron de fuente y que no han llegado hasta nosotros. Su visión es sobre todo social y no política. No es una crítica contra el poder o las distintas formas de gobierno sino contra los poderosos y la injusticia social.

Lo más probable es que Fedro haya sido influido en este tema, como en otros, por los principios de la filosofía estoica; en este caso, sobre todo, por la corriente más 
radical, representada por Antípatro, Blosio, etc., que denunciaba la injusticia social y protegía a los oprimidos. Esa influencia de la doctrina estoica se pudo ver fortalecida por circunstancias personales, ya que Fedro sufrió en carne propia las desventuras de una sociedad injusta.

Estas ideas de Fedro, tan características y originales, se fueron perdiendo paulatinamente en las versiones de sus fábulas que hicieron los fabulistas medievales y modernos continuadores del fabulista romano.

\section{Bibliografía}

Bajoni, M.G. (1999), «Il tempo dello schiavo: alcune osservazioni a Phaedr. 5,8» Philologus 143 (2), 317-322.

Caputi, R. (1998), «La volpe e l'aquila in Fedro e in Gualtiero Anglico», F. Bertini (ed.), Favolisti latini medievali e humanistici, VII, Génova, Università di Genova, 17-28.

Cascón Dorado, A. (1986), «Fedro en Samaniego», Revista de Filología Románica, (Uvinersidad Nacional de Educación Distancia), IV, 249-270.

Cascón Dorado, A. (2002), «Fedro y Samaniego: influjo estilístico y cambios ideológicos», Aldama, A. M. et alii (eds.), Noua et uetera: Nuevos horizontes de la Filología Latina, Madrid, Sociedad de Estudios Latinos, vol. II, 661-670.

Cascón Dorado, A. (2005), Fedro, Fábulas. Aviano, Fábulas. Fábulas de Rómulo. Madrid, Gredos.

Cascón Dorado, A. (2016), «Fedro protagonista de sus fábulas», RELat, 16, 83-100.

Champlin, E. (2005), «PhaedrusThe fabulous», JRS, 95, 97-123.

De Lorenzi, A. (1955), Fedro, La Nuova Italia, Firenze.

Della Corte, F. (1939), «Phaedriana», RFIC, 17, 163-144.

Gaide, F. (1980), Avianus. Fables, Paris, Les Belles Lettres.

García Gual, C. (1983), «La fábula esópica. Estructura e ideología de un género popular», in García Arias, J.L. et alii (eds.), Estudios ofrecidos a E. Alarcos, Oviedo, Universidad de Oviedo, vol. I, 309-322.

Gärtner, U. (2007), «Levi calamo ludimus. Zum poetologischen Spiel bei Phaedrus», Hermes $135,2007,429-459$,

Gärtner, U. (2011), «Palam muttire plebeio piaculum est, die Fabeln des Phaedrus als literarische Kommunikationsform in der frühen kaiserzeit», Haltenhold, A. et alii (eds.), Römische Werte und römische Literatur im frühen Prinzipat, Berlin/New York, De Gruyter, 253-277.

Gasparov, L. M. (1968): «Sjuzet i ideologiya v ezopovskich basnjach», Vjestnik Drevnjej Istorii, 105, 116-126.

Gatti, P. (2004), «Fedro ‘nuovo' da Ademaro? », Paideia, 59, 197-214.

Gaudemet, J. (1967), Institutions de l'Antiquité, Paris, Sirey.

Glauthier P. (2009), «Callimachus and the recusatio to Success», ClAnt 28, 248-278.

Henderson J. (2001), Telling Tales on Caesar. Roman Stories from Phaedrus, Oxford, Oxford University Press.

Herrmann, L. (1963-1964), «Phèdre et La Fontaine», Journées d'études, 36, 75-90.

Luzzatto, M. J. (1976), Fedro. Un poeta tra favola e realtà, Torino, Paravia.

La Penna, A. (1961), «La morale della favola esópica come morale delle classi subalterne nell' Antichità», Società, 17, 459-537. 
La Penna, A. (1974), Introducción a Fedro. Favole (ed. A. Richelmy), Torino, Einaudi

Lelli, E. (2001), «Pindaro, Fedro e la protesta degli umili», GIF, 53 (1), 69-72

Mandruzzatto, E. (1979), Fedro. Favole, Milano, Rizzoli.

Mañas Nuñez, M. (1998), Fedro/Aviano. Fábulas, Madrid, Akal.

Marchesi, C. (1923), Fedro e la favola latina, Firenze, Vallechi.

Mattiacci, S. (2014), «Il liberto 'greco' in cerca di un'identità romana: autorappresentazione e programa letterario in Fedro», Mordeglia C. (ed.) 'Lupus in fabula'. Fedro e la favola latina tra Antichità e Medioevo. Studi offerti a Ferruccio Bertini, Bologna, Pàtron, 49-71.

Moller Jensen, B. (2004), «'Societas leonina” or the lion's share: an analysis of Aesopica 149 (Hsr.), Phaedrus I 5 and Babrius I 67», Eranos, 102 (2), 97-104.

Mordeglia, C. (2014), «Fedro, Augusti libertus (?), e il potere», Paideia, LXIX, 119-155.

Mordeglia, C. (2016), «Lo stile della favola esopica: il caso di Fedro e Aviano e dei loro rifacimenti tardoantichi e mediolatini» Maia 68, 2016, 735-765.

Nicolet, C. (1965), «L' inspiration de Tibèrius Gracchus», REA, 67, 142-158.

Nøjgaard, M. (1964), La fable antique I: la fable grecque avant Phèdre. Kobenhaun.

Nøjgaard, M. (1967), La fable antique II: les grands fabulistes, Kobenhaun.

Rodríguez Adrados, F. (1977), Historia de la fábula greco-latina, I, Madrid, Universidad Complutense.

Rodríguez Adrados, F. (1987), «Política cínica en las fábulas esópicas», Filologia e forme letterarie. Studi offerti a Francesco Della Cortte, I, Urbino, 413-426.

Renda, C. (2012), Illiteratum plauso nec desidero. Fedro, la favola, la poesia. Napoli, Loffredo.

Rostagni, A. (1964), Storia della letteratura latina, Torino, Unione Tipográfico Editrice Torinese.

Solana Dueso, J. (2015), «Estoicismo y política: líneas de confrontación», Azafea, Revista de filosofía (Universidad de Salamanca), 17, 75-95.

Stocchi, Ch. (2005), «La dialettica socioeconomica nei promiti fedriani: (Phaedr. I 24, 1; I 27 , 1 s.; I 28, 1 s.; I 30,1) » Lexis, 23, 295-303.

Thiele G. (1910), Der lateinische Aesop des Romulus, Heidelberg, Carl Winter's Univ.

Waltz, R. (1954), «Phèdre et La Fontaine», L'Information littéraire, VI, 89-97.

Zander, C. (1921), Phaedrus solutus vel Phaedri fabulae nouae XXX, Lund, C.W.K. Gleerup. 